\title{
Synthesis of SAPO-34 catalysts via sonochemically prepared method and its catalytic performance in methanol conversion to light olefins
}

\author{
Rana Ahmadova $^{1}$ [ $\cdot$ Hikmet Ibragimov ${ }^{1} \cdot$ Evgenii Kondratenko $^{2} \cdot$ Uwe Rodemerc $^{2}$
}

Received: 3 October 2017 / Accepted: 7 February 2018 / Published online: 14 February 2018

(C) The Author(s) 2018. This article is an open access publication

\begin{abstract}
Methanol-to-olefin (MTO) reaction was investigated over sonochemically (SAPO-34-U40, SAPO-34-U70, SAPO-34-U100) and hydrothermally (SAPO-34-HT) prepared nanocatalysts. The catalytic performance of prepared samples was investigated over all samples at $450{ }^{\circ} \mathrm{C}$ and over SAPO-34-U40 at 350-450 ${ }^{\circ} \mathrm{C}$ temperature range. The higher yield $\sim 97 \mathrm{wt} \%(31.4 \mathrm{wt} \%$ $\mathrm{C}_{2=}, 49.4 \mathrm{wt} \% \mathrm{C}_{3=}$ and $16.1 \mathrm{wt} \% \mathrm{sumC}_{4=}$ ) of light olefins was obtained at $375^{\circ} \mathrm{C}$ on SAPO-34-U40. Physico-chemical properties of catalysts were characterized by XRD, SEM, BET, ICP techniques. XRD analysis showed suitable crystalline structure and SEM images confirmed perfect crystallinity of sonochemically prepared samples. BET analysis indicated remarkable surface area of SAPO-34-U40. The amount of carbon deposits and character of coke was determined by TPO analysis. The higher amount of coke was determined over SAPO-34-HT in comparison to another's at $450{ }^{\circ} \mathrm{C}$. The character of coke deposited over SAPO-34-U40 was similar for $375-425^{\circ} \mathrm{C}$ temperatures.
\end{abstract}

Keywords SAPO-34 $\cdot$ Ultrasound $\cdot$ Hydrothermal $\cdot$ Nanocatalyst $\cdot$ Catalytic performance $\cdot$ MTO

\section{Introduction}

Light olefins such as ethylene and propylene are widely used as raw materials for large-scale production of various polymers, fibers, resins and solvents. Owing to the rapid development of the world economy, there is increased demand for ethylene and particularly for propylene. Methanol-to-olefin (MTO) process has attracted attention as a potential indirect route for the production of light olefins, because methanol is commercially produced from synthesis gas generated from natural gas and/or coal [1].

Silicoaluminophosphate molecular sieve, especially SAPO-34 catalyst is one of the best candidates for the process of obtaining light olefins from methanol. Because of

Rana Ahmadova

rena_ax@rambler.ru

1 Department of "Chemistry and Technology of Oil and Gas", Institute of Petrochemical Processes named after Yu.G.Mamedaliev, Azerbaijan National Academy of Sciences, Khojaly Ave. 30, 1025 Baku, Azerbaijan

2 Department of "Catalyst Discovery and Reaction Engineering”, Leibniz Institute for Catalysis, University of Rostock, Albert-Einstein-Str. 29a, 18059 Rostock, Germany its CHA framework and small particle sizes, SAPO-34 enhances the accessibility of methanol into its cages and leads to better catalytic performance [2,3]. The main inability which makes the lifetime of SAPO-34 catalysts short is a fast deactivation because of accumulation of large aromatic species inside the cages of these catalysts. In this case, preparing of catalysts which are more resistance to coke formation is one of the main problems [4-6].

Until now, many researches have mainly focused on the different synthesis methods which are effect on the various properties of SAPO-34, such as catalyst acidity, pore size and shape, particle size, etc. [7-9]. Last few years, great attention has been paid to the use of ultrasound energy. The main advantages of SAPO-34 synthesized by this method are: to obtain higher surface area with narrow size distribution and enhanced catalytic performance. It was proved by many researches that ultrasonic treatment prevents the further growth of the particles and their agglomeration. Furthermore, achieving smaller particles decline the secondary reactions in MTO process [10-14]. Therefore, in this work the effect of ultrasound wave's frequency on physicochemical properties and catalytic activity of synthesized SAPO-34 have been studied and are compared with SAPO-34 catalyst, synthesized using conventional hydrothermal method. To this end, synthesized via ultrasound treatment SAPO-34 
catalyst's catalytic performance was investigated at different temperatures in MTO reaction. The catalysts were characterized by XRD, SEM, ICP, BET and TPO analysis.

\section{Materials and methods}

\section{Materials}

Boehmite (CAPATAL B, 70.5\% $\mathrm{Al}_{2} \mathrm{O}_{3}$ ), tetraethylorthosilicate (TEOS, Merck, $\geq 98 \%$ ) and ortho-phosphoric acid (Aldrich, 85\%) were used as sources of aluminum, silicon and phosphorus, respectively. The tetraethyl ammonium hydroxide (TEAOH, ALDRIX, $35 \mathrm{wt} \%$ aqueous solution) was applied as template for SAPO-34 synthesis. All materials were used as received without any further treatments. The catalysts, synthesized by hydrothermal method (HT) and by ultrasound waves with 40,70 and $100 \%$ powers $(8,14$ and $20 \mathrm{kHz}$ ), were further abbreviated as SAPO-34-HT, SAPO34-U40, SAPO-34-U70 and SAPO-34-U100, respectively.

\section{Catalyst preparation and procedures}

To synthesize active catalysts with desirable properties, adding and mixing are main clauses. So, for the preparation of SAPO-34 catalysts using ultrasound waves, for avoiding of creating of lumps, $6.5 \mathrm{~g}$ boehmite was gradually (approximately $2 \mathrm{~h}$ ) added to $32.3 \mathrm{~g}$ TEAOH and during adding the power for stirring was increased. Mixture was stirred for $90 \mathrm{~min}$; then $2.4 \mathrm{~g}$ TEOS was added drop-wise and solution stirred additional for $60 \mathrm{~min}$. Afterwards, $8.9 \mathrm{~g}$ of phosphoric acid diluted in $12.7 \mathrm{~g}$ of distilled water was added drop-wise; at the end, remaining water was added to the mixture. The final gel was sonicated in argon flow for $30 \mathrm{~min}$, by an Ultrasonic Homogenizer SONOPLUS HD 2070 (Bandelin) with a frequency of $20 \mathrm{kHz}$ and input power of $70 \mathrm{~W}$. The $\mathrm{pH}$ of gel was 7. For preparation of SAPO-34 catalyst via hydrothermal method, the same components were mixed without using ultrasound frequency. In both synthesis methods, final mixture was transferred into stainless steel autoclaves and heated at $200{ }^{\circ} \mathrm{C}$ for $48 \mathrm{~h}$. Temperature of crystallization was controlled by temperature controller. After crystallization, samples were centrifuged and washed twice with distilled water. Then, the synthesized samples were dried at $110{ }^{\circ} \mathrm{C}$ for $12 \mathrm{~h}$, at the end calcined at $550{ }^{\circ} \mathrm{C}$ in the air for $12 \mathrm{~h}$ to remove the organic template molecules. Prior to the catalytic tests, the catalysts were pelleted, crushed and sieved into $250-600 \mu \mathrm{m}$ fraction.

\section{Catalyst characterization}

The crystallographic properties of calcined samples were analyzed by X-ray diffraction (XRD) using a PANanalytical
$\mathrm{X}^{\prime}$ Pert Pro powder with $\mathrm{Cu} \mathrm{K} \alpha$ radiation $\mathrm{X}$-ray (wavelength $\lambda=0.15 \mathrm{~nm}$ ). XRD patterns were recorded in the range of $0^{\circ}-40^{\circ}(2 \theta)$. The crystal morphology and crystal size were analyzed by scanning electron microscopy (SEM, Bruker). The metal content of the calcined catalysts was determined by inductively coupled plasma optical emission spectroscopy (ICP-OES, Varian 715-ES). The specific surface areas of synthesized catalysts were calculated from $\mathrm{N}_{2}$ adsorption-desorption isotherms collected at $77 \mathrm{~K}$ on a BELSORPmini II (BEL Japan). The Brunauer, Emmett and Teller (BET) equation was applied for an $\mathrm{N}_{2}$ relative pressure range of $P / P_{0}=0.05-0.3$. The amount of carbon deposits formed over catalysts during MTO process was determined from TPO analysis using a quadrupole mass spectrometer (Pfeiffer Vacuum OmniStar 200).

\section{Continuous flow catalytic tests}

MTO tests over SAPO-34 catalysts were performed in a multi-channel set-up consisting of 15 plug flow fixed-bed quartz tube reactor (i.d. $=3.8 \mathrm{~mm}$ ), at $350-450{ }^{\circ} \mathrm{C}$ temperature, and 1.2 bar, for $7 \mathrm{~h}$ on stream using $\mathrm{CH}_{3} \mathrm{OH} / \mathrm{N}_{2}=60 / 40$ feed with a modified contact time of $2.05 \mathrm{~g}_{\text {cat }}$ min $\mathrm{ml}^{-1}$ with respect to methanol. Each reactor was filled with $200 \mathrm{mg}$ of fresh catalyst. Before reaction catalysts were heated to request temperature of process (different temperatures, from 350 to $\left.450{ }^{\circ} \mathrm{C}\right)$ in air $\left(13 \mathrm{ml} \mathrm{min}{ }^{-1}\right.$ per channel) held in air flow for $2 \mathrm{~h}$ and then flushed with $\mathrm{N}_{2}$ for $30 \mathrm{~min}$. Hereafter, a mixture of $60 \mathrm{vol} \% \mathrm{CH}_{3} \mathrm{OH}$ in $\mathrm{N}_{2}$ was fed into the catalyst bed at a rate of $10 \mathrm{ml} \mathrm{min}^{-1}$ per reactor. After, experiment reactors were cooled to room temperature in $\mathrm{N}_{2}$.

The feed components and the reaction products were analyzed using an on-line gas chromatograph (Agilent 6890) equipped with PLOT/Q (for $\mathrm{CO}_{2}$ ), HP-PLOT $\mathrm{Al}_{2} \mathrm{O}_{3}$ " $\mathrm{KCl}$ " (for hydrocarbons) and Molsieve 5 (for $\mathrm{H}_{2}, \mathrm{O}_{2}, \mathrm{~N}_{2}$, and $\mathrm{CO})$ columns and flame ionization and thermal conductivity detectors. The GC analysis was carried out reactor by reactor.

\section{Calculation of carbon deposits}

The amount of carbon of discharged catalysts after MTO reaction was determined from the amounts of $\mathrm{CO}$ and $\mathrm{CO}_{2}$ evolved during temperature-programmed oxidation (TPO). The TPO measurements were performed in a setup equipped with eight individually heated plug-flow fixed-bed quartz tube reactors (i.d. $=6.9 \mathrm{~mm}$ ). The used catalysts were heated to $900{ }^{\circ} \mathrm{C}$ in a flow $\left(10 \mathrm{ml} \mathrm{min}^{-1}\right)$ of 10 vol $\% \mathrm{O}_{2}$ in Ar. The measurements were performed successively, i.e., during heating (TPO) of the analyzed sample; all other samples were kept at $25{ }^{\circ} \mathrm{C}$ under Ar. Oxygen consumption and formation of the reaction products were monitored using a quadrupole mass spectrometer 
(Pfeiffer Vacuum OmniStar 200). The following atomic mass units (AMUs) were obtained: $44\left(\mathrm{CO}_{2}\right), 40$ (Ar), 32 $\left(\mathrm{O}_{2}\right), 28\left(\mathrm{CO}, \mathrm{CO}_{2}\right)$, and $18\left(\mathrm{H}_{2} \mathrm{O}\right)$. The concentrations of $\mathrm{O}_{2}, \mathrm{CO}$ and $\mathrm{CO}_{2}$ were determined from the respective AMUs using standard fragmentation patterns and sensitivity factors determined by analyzing calibration gas mixtures.

\section{Results and discussion}

\section{Catalyst characterizations}

\section{XRD analysis}

The XRD patterns of synthesized SAPO-34-HT, SAPO34-U40, SAPO-34-U70 and SAPO-34-U100 catalysts are shown in Fig. 1.
Fig. 1 XRD patterns of the nanostructured SAPO-34-HT, SAPO-34-U40, SAPO-34-U70 and SAPO-34-U100 catalysts

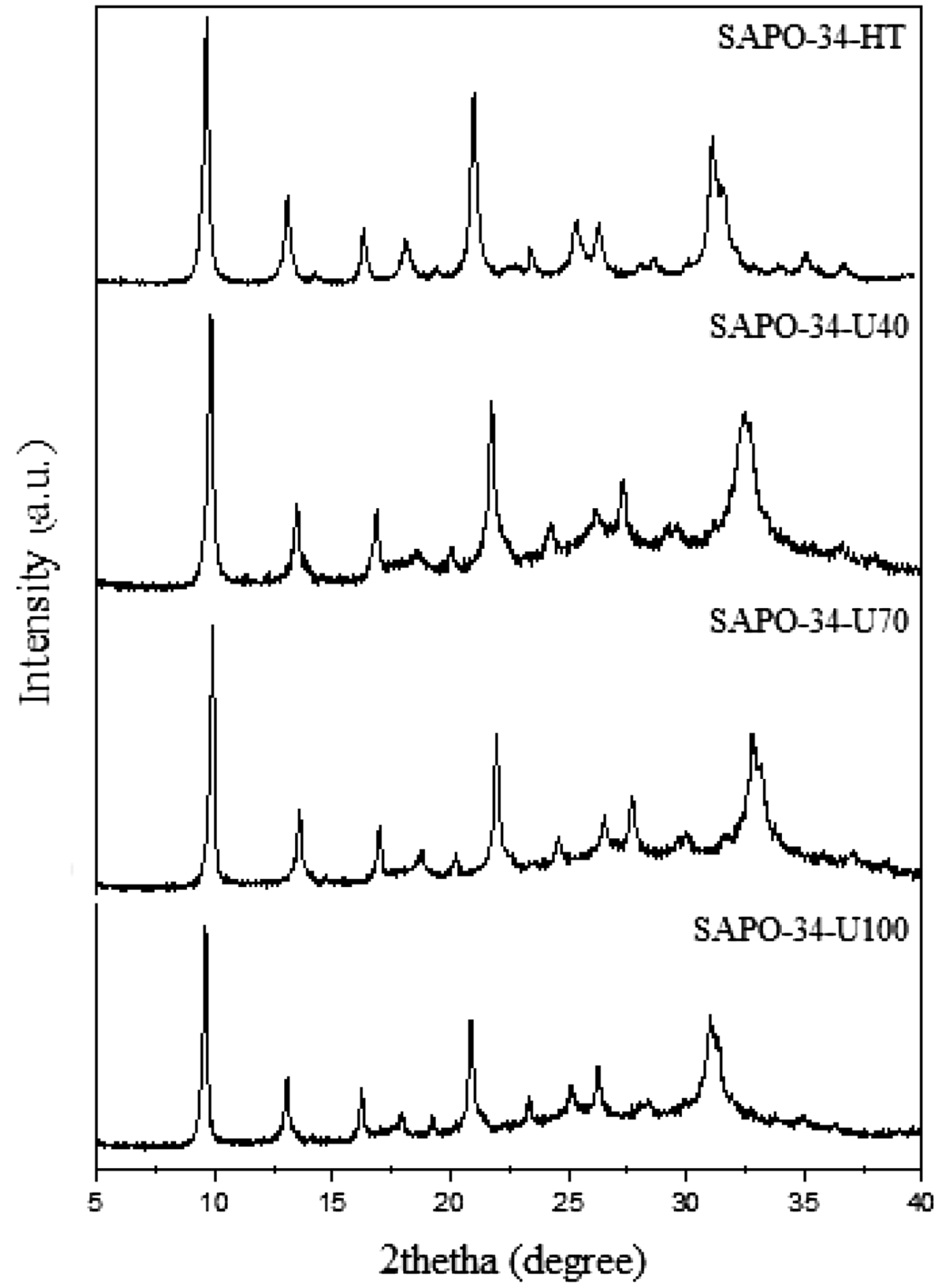


All synthesized samples demonstrate typical powder diffraction patterns corresponding to CHA structure of SAPO34, without any presence of impurity phase. The XRD peak intensity for all SAPO-34 samples was determined at $2 \theta=9.58^{\circ}, 12.9^{\circ}, 16.25^{\circ}, 20.87^{\circ}, 23.3^{\circ}, 25.1^{\circ}, 26.2^{\circ}$ and $31^{\circ}$ [10]. The crystallinity of SAPO-34-HT, SAPO-34-U40, SAPO-34-U70 and SAPO-34-U100 was found to be 60, 70, 68 and $65 \%$, respectively. The average crystallite sizes (nm) were calculated using the Scherrer equation:

$D=\frac{k \lambda}{\beta \cos \theta}$

where $k$ is a constant, $\lambda$ is the wavelength of the $\mathrm{X}$-ray, $\beta$ is the full width of diffraction peak at half maximum intensity, $\theta$ is the diffracting angle [15]. Table 1 presents some properties, also the XRD results of synthesized SAPO-34 samples. All catalysts are in cubic form, and average crystallite size calculated for SAPO-34-HT, SAPO-34-U40, SAPO-34-U70 and SAPO-34-U100 are 45, 27, 27.9 and $28.2 \mathrm{~nm}$, respectively. It can be concluded that in comparison to hydrothermal method, ultrasound irradiation of gel leads to obtaining of lower average crystallite size. Also, different frequency of used ultrasound waves has a slightly influence to crystallinity and crystal size of synthesized samples.

\section{SEM analysis}

The SEM analysis of synthesized samples is shown in Fig. 2. Synthesized catalysts are in cubic structure and this structure is similar to chabazite [8, 16-19].

SEM images show that using conventional hydrothermal method, cubic crystals with size of $<300 \mathrm{~nm}$ are obtained for SAPO-34-HT, but applying ultrasound waves to the synthesize of catalysts gives small cubic crystals with size of $<100 \mathrm{~nm}$ for SAPO-34-U40, SAPO-34-U70 and SAPO34-U100. In addition, it is obvious that (Fig. 2a-c), relatively uniform particles were obtained for SAPO-34 catalysts, synthesized using ultrasound treatment. So, ultrasound irradiation of gel improves uniformity of the synthesized samples, and also gives possibility to obtain small cubic crystals.

\section{BET analysis}

Specific surface areas of synthesized SAPO-34 catalysts are given in Table 1. Because of synthesized samples are microporous materials, specific surface areas were determined by " $t$-plot" method. According to this analysis, the surface of internal micropores of SAPO-34-HT, SAPO34-U40, SAPO-34-U70 and SAPO-34-U100 were obtained $358.58,887.8,713.8$ and $704.77 \mathrm{~m}^{2} \mathrm{~g}^{-1}$, external surface of samples 75.42, 100.1, 97.44 and 98.92, respectively. Thus, SAPO-34-HT has lower $\left(434 \mathrm{~m}^{2} \mathrm{~g}^{-1}\right)$ specific surface area; SAPO-34-U40 possesses a higher specific surface area $\left(987.9 \mathrm{~m}^{2} \mathrm{~g}^{-1}\right)$ in comparison to SAPO-34-U70 and

Table 1 Element content (wt\%) and structural properties of nanostructured SAPO-34-HT, SAPO-34-U40, SAPO-34-U70 and SAPO-34-U100 catalysts

\begin{tabular}{|c|c|c|c|c|c|c|c|c|c|c|}
\hline \multirow[t]{2}{*}{ Samples } & \multicolumn{4}{|c|}{ Element content (wt\%) } & \multicolumn{3}{|c|}{ Surface area $\left(\mathrm{m}^{2} \mathrm{~g}^{-1}\right)$} & \multirow{2}{*}{$\begin{array}{l}\text { Average crystal- } \\
\text { lite size }(\mathrm{mm})\end{array}$} & \multirow{2}{*}{$\begin{array}{l}\text { Relative crys- } \\
\text { tallinity }(\%)\end{array}$} & \multirow{2}{*}{$\begin{array}{l}\text { Product } \\
\text { phase } \\
\text { SAPO-34 }\end{array}$} \\
\hline & $\mathrm{Al}$ & $\mathrm{Si}$ & $\mathrm{P}$ & $\mathrm{O}$ & $S_{\mathrm{BET}}$ & $S_{\text {micropore }}$ & $S_{\text {external }}$ & & & \\
\hline SAPO-34-HT & 21 & 7 & 16 & 56 & 434 & 358.58 & 75.42 & 45 & 60 & Cubic \\
\hline SAPO-34-U40 & 17.5 & 5.9 & 15.8 & 60.8 & 987.9 & 887.78 & 100.12 & 27 & 70 & Cubic \\
\hline SAPO-34-U70 & 18.0 & 6.4 & 16 & 59.6 & 811.2 & 713.76 & 97.44 & 27.9 & 68 & Cubic \\
\hline SAPO-34-U100 & 18.5 & 6.2 & 16.6 & 58.7 & 804.7 & 704.77 & 98.92 & 28.2 & 65 & Cubic \\
\hline
\end{tabular}
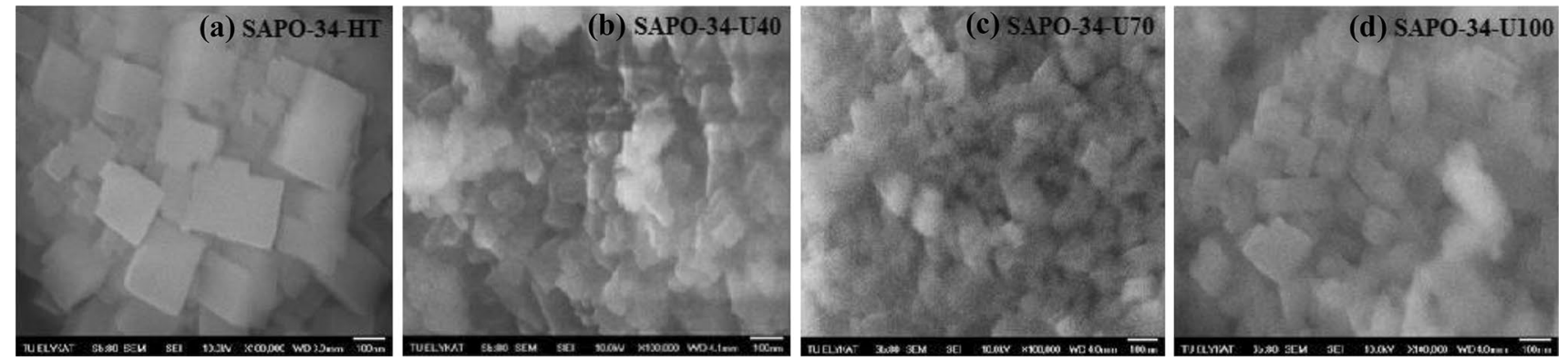

Fig. 2 SEM images of nanostructured catalysts: a SAPO-34-HT, b SAPO-34-U40, c SAPO-34-U70 and d SAPO-34-U100 


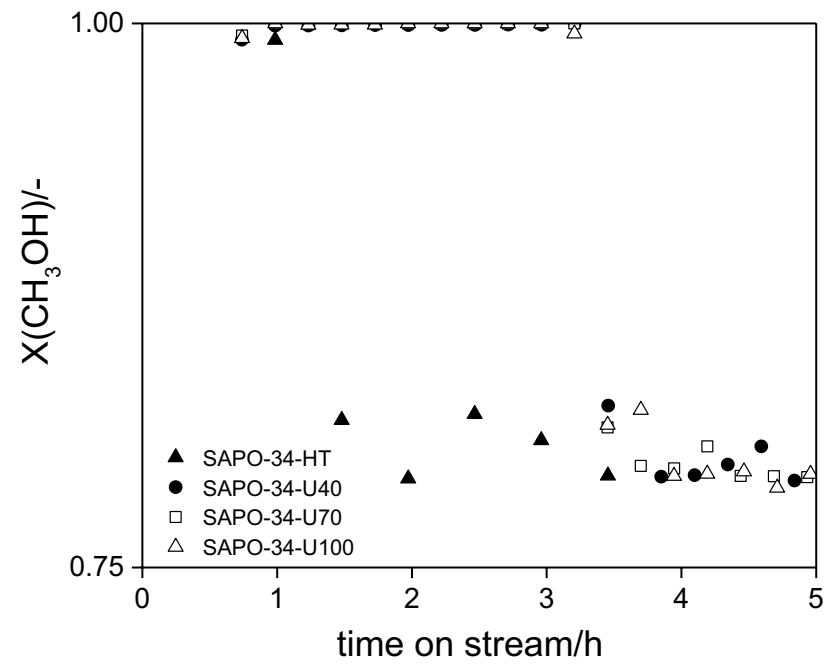

Fig. 3 Conversion of methanol over nanostructured SAPO-34-HT (filled triangle), SAPO-34-U40 (filled circle), SAPO-34-U70 (open square) and SAPO-34-U100 (open triangle) catalysts. Reaction conditions: $450{ }^{\circ} \mathrm{C}, \mathrm{CH}_{3} \mathrm{OH} / \mathrm{N}_{2}=60 / 40$, contact time $=2.05 \mathrm{~g}_{\text {cat }} \mathrm{min} \mathrm{ml} \mathrm{m}^{-1}$ with respect to methanol, catalyst $=0.2 \mathrm{~g}$
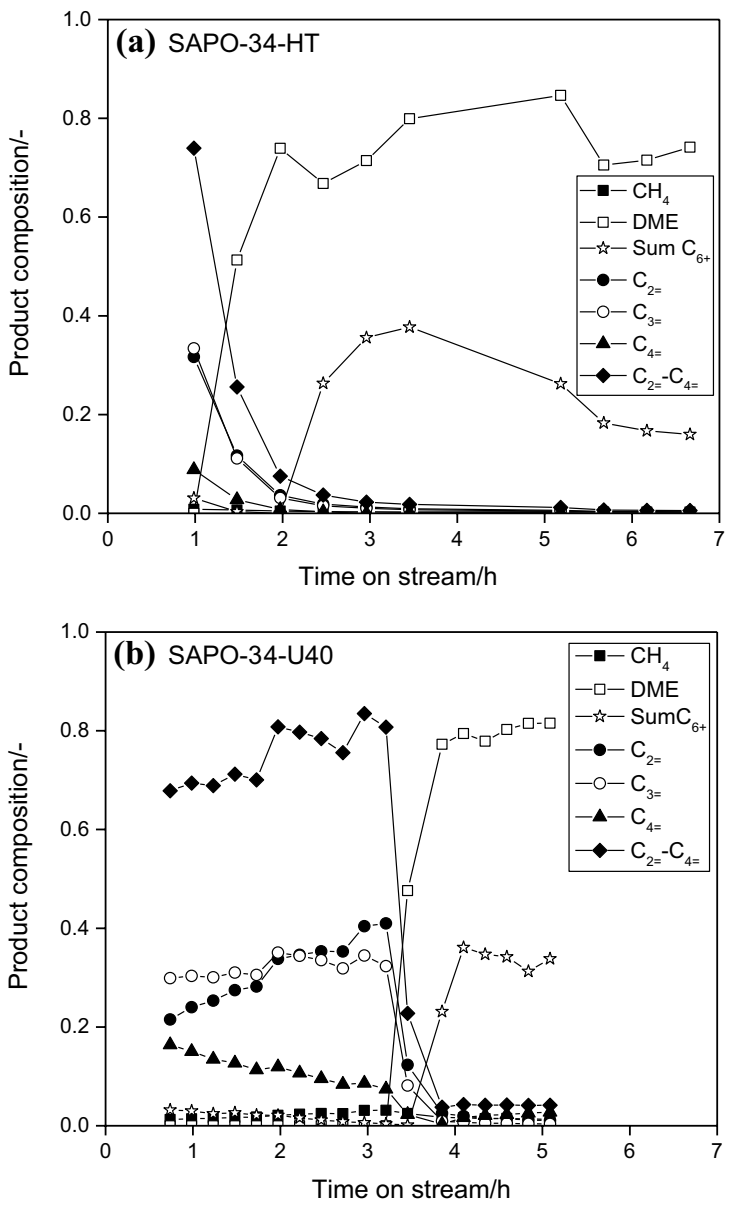

SAPO-34-U100 (811.2 and $\left.804.7 \mathrm{~m}^{2} \mathrm{~g}^{-1}\right)$. The surface area analysis showed that ultrasound treatment of gel increases specific surface area of catalysts.

\section{Catalytic performance}

Methanol conversion (Fig. 3) over all samples synthesized using ultrasound waves reaches $100 \%$ during 3 -h of reaction time, then decreases to $79 \%$ with deactivation of catalysts. All catalysts (SAPO-34-U40, SAPO-34-U70, SAPO-34-U100) show approximately similar results. On the contrary, SAPO-34-HT is active only $1 \mathrm{~h}$ and after $1.4 \mathrm{~h}$ methanol conversion decreases to $80 \%$. Comparison between SAPO-34-HT and SAPO-34-U40, SAPO-34-U70 and SAPO-34-U100 performances on methanol conversion approves better activity of SAPO-34 catalysts, synthesized via ultrasound treatment, for MTO reaction.

Figure 4 illustrates synthesized catalysts performance toward light olefins, $\mathrm{CH}_{4}$, DME and sumC $6+$ production. Over all synthesized catalysts $\mathrm{C}_{2=}-\mathrm{C}_{4=}$ olefins were main reaction products; $\mathrm{DME}$ and $\mathrm{sumC}_{6+}$ major by-products
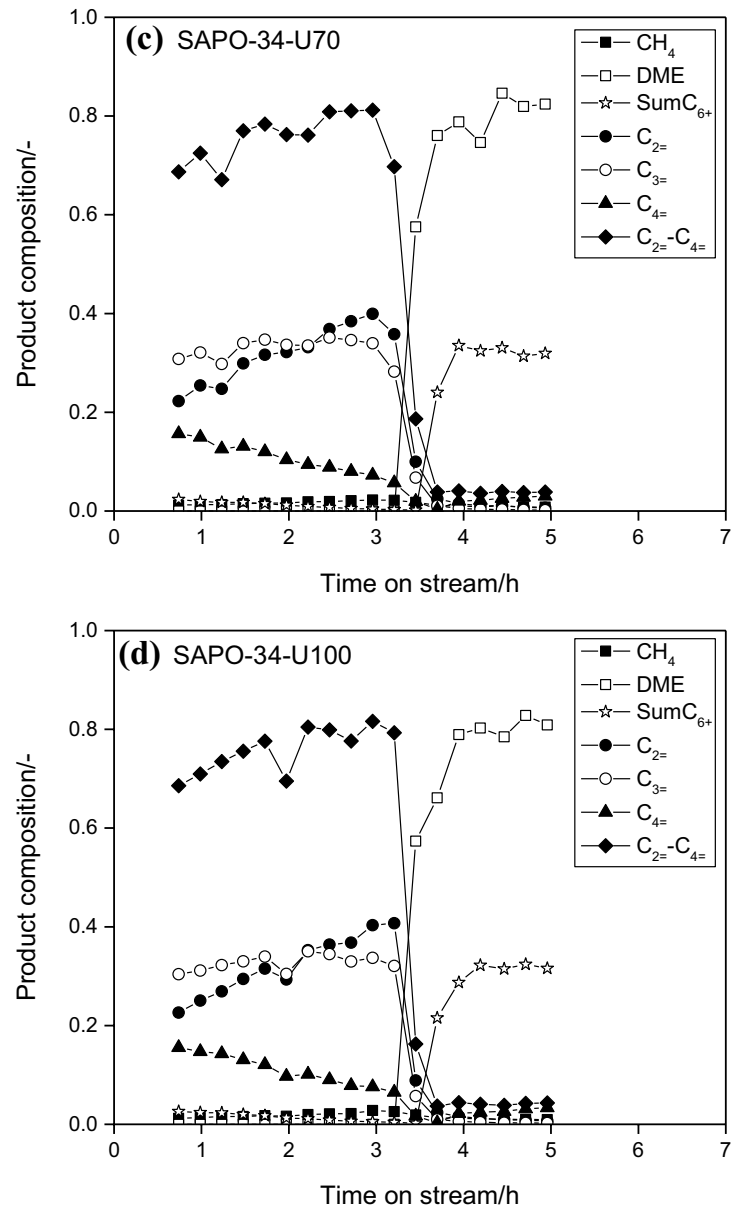

Fig. 4 Product distribution in the MTO reaction over nanostructured a SAPO-34-HT, b SAPO-34-U40, c SAPO-34-U70 and d SAPO-34-U100 catalysts. Reaction conditions: $450{ }^{\circ} \mathrm{C}, \mathrm{CH}_{3} \mathrm{OH} / \mathrm{N}_{2}=60 / 40$, contact time $=2.05 \mathrm{~g}_{\text {cat }}$ min ml ${ }^{-1}$ with respect to methanol, catalyst $=0.2 \mathrm{~g}$ 
were detected with deactivation of catalysts, while $\mathrm{CH}_{4}$ was formed in low amounts.

Comparison between SAPO-34-U40, SAPO-34-U70 and SAPO-34-U100 performances on $\mathrm{C}_{2=}-\mathrm{C}_{4=}$ production approves same activity of samples for MTO reaction. The yield of low olefins increases with time on stream and at $3 \mathrm{~h}$ it reaches 83.5, 81.2 and $81.6 \mathrm{wt} \%$ for SAPO-34-U40, SAPO-34-U70 and SAPO-34-U100, respectively. Over SAPO-34-HT, yield of light olefins is $73.9 \mathrm{wt} \%$ during $1 \mathrm{~h}$, after $1.4 \mathrm{~h}$ with rapid deactivation of catalyst it decreases to $25 \mathrm{wt} \%$. Thus, the lowest activity of SAPO-34-HT catalyst corresponds to its lower crystallinity and lower surface area which are important factors affecting deactivation of the catalyst [20].

The decrease in light olefins formation for all samples corresponds to an increase in the formation of DME and higher hydrocarbons. All catalysts present a high content of dimethyl ether after $3.4 \mathrm{~h}$ (for SAPO-34-U40, SAPO-34-U70 and SAPO-34-U100) and after $1.4 \mathrm{~h}$ (for SAPO-34-HT) of TOS as shown in Fig. 4. The high yield of DME can be attributed to the deactivation of the stronger acid centers of the catalysts, which are able to produce the dehydration of DME to the light olefins [12]. With deactivation of catalysts, the role of secondary reactions take place and this factor leads to formation of higher hydrocarbons $\left(\mathrm{C}_{6+}\right)$.

As the results of MTO process over sonochemically synthesized samples are similar, we decided to use SAPO34-U40 (which possesses higher surface area and smaller crystallite size) for further investigations. So, this sample was undergone to methanol-to-olefin tests at different temperatures. Figures 5 and 6 show the methanol conversion and

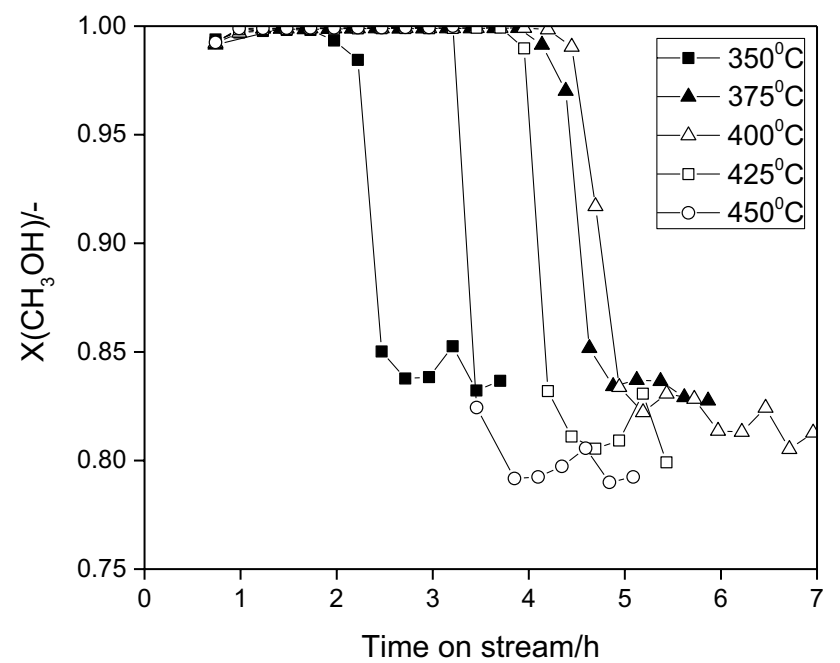

Fig. 5 Methanol conversion vs. temperature over nanostructured SAPO-34-U40 catalyst. Reaction conditions: $\mathrm{CH}_{3} \mathrm{OH} / \mathrm{N}_{2}=60 / 40$, contact time $=2.05 \mathrm{~g}_{\text {cat }} \mathrm{min} \mathrm{ml}^{-1}$ with respect to methanol, catalyst $=0.2 \mathrm{~g}$

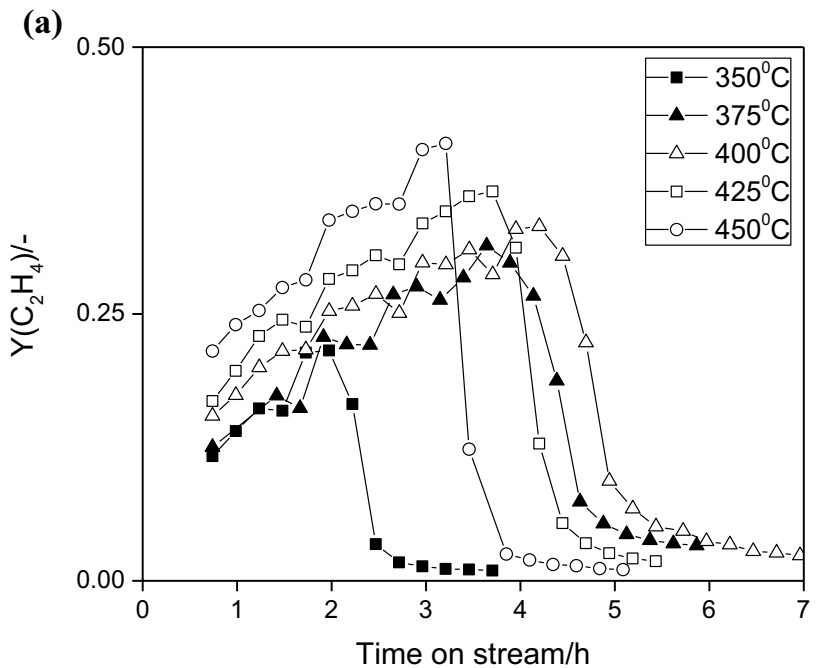

(b)
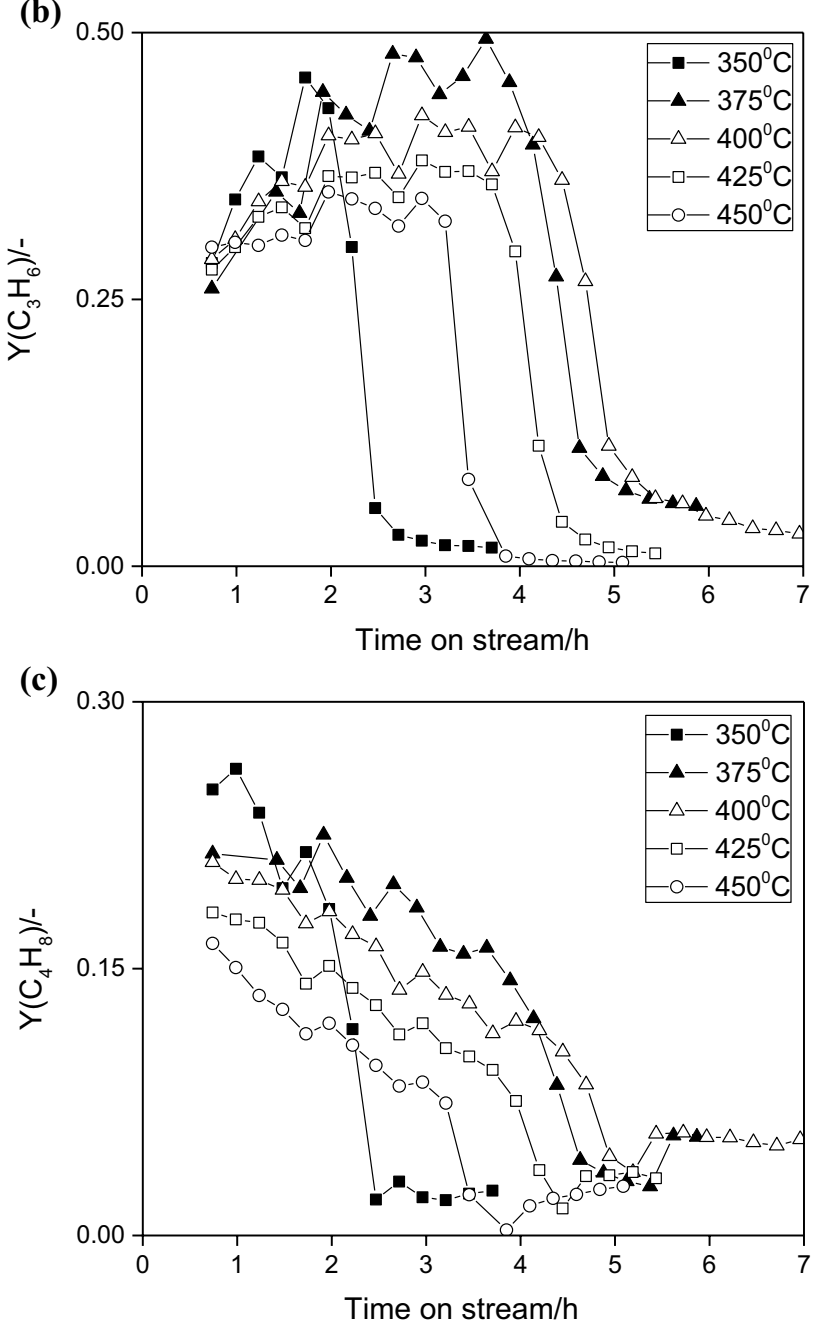

Fig. 6 Ethylene (a), propylene (b) and butylene's (c) yield vs. temperature over nanostructured SAPO-34-U40 catalyst. Reaction conditions: $\mathrm{CH}_{3} \mathrm{OH} / \mathrm{N}_{2}=60 / 40$, contact time $=2.05 \mathrm{~g}_{\text {cat }}$ min ml $\mathrm{ml}^{-1}$ with respect to methanol, catalyst $=0.2 \mathrm{~g}$ 
product $\left(\mathrm{C}_{2=}, \mathrm{C}_{3=}\right.$ and $\left.\mathrm{C}_{4=}\right)$ yield as a function of time on stream on SAPO-34-U40 catalyst at different temperatures.

At lower $\left(350{ }^{\circ} \mathrm{C}\right)$ and higher $\left(450{ }^{\circ} \mathrm{C}\right)$ temperatures, methanol conversion and general yield of light olefins decrease faster than at medium temperatures, showing that catalyst deactivates faster at lower and higher temperatures. The yield of DME increases with decreasing yield of light olefins. It can be explained with two conclusions for this study. First, secondary reactions (hydrogen transfer, alkylation and others), which take place at higher temperatures, lead to coke formation resulting in deactivation of catalyst. With blocking of small pores inside the catalyst, DME formation occurs over external surface of SAPO-34 on the weak acidic sites. Second, lower temperature is not enough for cracking of bulky oligomers and they are remaining in inside channels of catalyst, causing deactivation. Therefore, the conversion reaction of methanol to DME takes place at the external surface of catalyst. Also, it was observed that at higher temperature $\left(450{ }^{\circ} \mathrm{C}\right)$ yield of ethylene decreases, which is explained with cracking of propylene and butenes at this temperature. Oligomerization and cracking reactions in some ways are balanced at medium temperatures and are not enough to generate too much coke [12,21]. Because of this reason catalyst deactivates slowly. Medium temperatures are working temperatures. From Figs. 5 and 6 it is clear that synthesized SAPO-34-U40 is more active and stable at $375{ }^{\circ} \mathrm{C}$ temperature. The yield of olefins reach approximately $97 \mathrm{wt} \%\left(31.4 \mathrm{wt} \% \mathrm{C}_{2=}, 49.4 \mathrm{wt} \% \mathrm{C}_{3=}\right.$ and $\left.16.1 \mathrm{wt} \% \mathrm{sumC}_{4=}\right)$ at $3.6 \mathrm{~h}$ reaction time. For our MTO tests over SAPO-34-U40 catalyst, which were conducted at several temperatures, $375{ }^{\circ} \mathrm{C}$ was found to be an optimal temperature.

\section{Coke formation}

The amount of carbon deposits formed during the MTO reaction was analyzed by TPO of spent catalysts after the 7-h experiment. The amount of carbon formed in MTO tests over SAPO-34-HT, SAPO-34-U40, SAPO-34-U70 and SAPO-34-U100 (at $450^{\circ} \mathrm{C}$ ) and SAPO-34-U40 (from 350 to $450{ }^{\circ} \mathrm{C}$ ) was determined by integrating the $\mathrm{CO}$ and $\mathrm{CO}_{2}$ profiles recorded in the TPO tests and the results are shown in Fig. 7.

The results (Fig. 7a) show that over SAPO-34-HT, SAPO34-U40, SAPO-34-U70 and SAPO-34-U100, the amount of carbon deposition per gram of the catalyst is $0.3,0.24,0.24$ and 0.22, respectively. Carbon deposition over SAPO-34-HT is higher in comparison to another samples, which is a reason of its low surface area, hence its fast deactivation. So, high surface area of the catalyst is helpful for the prolongation of its lifetime [22]. The amount of carbon deposition over samples synthesized using ultrasound waves is similar.
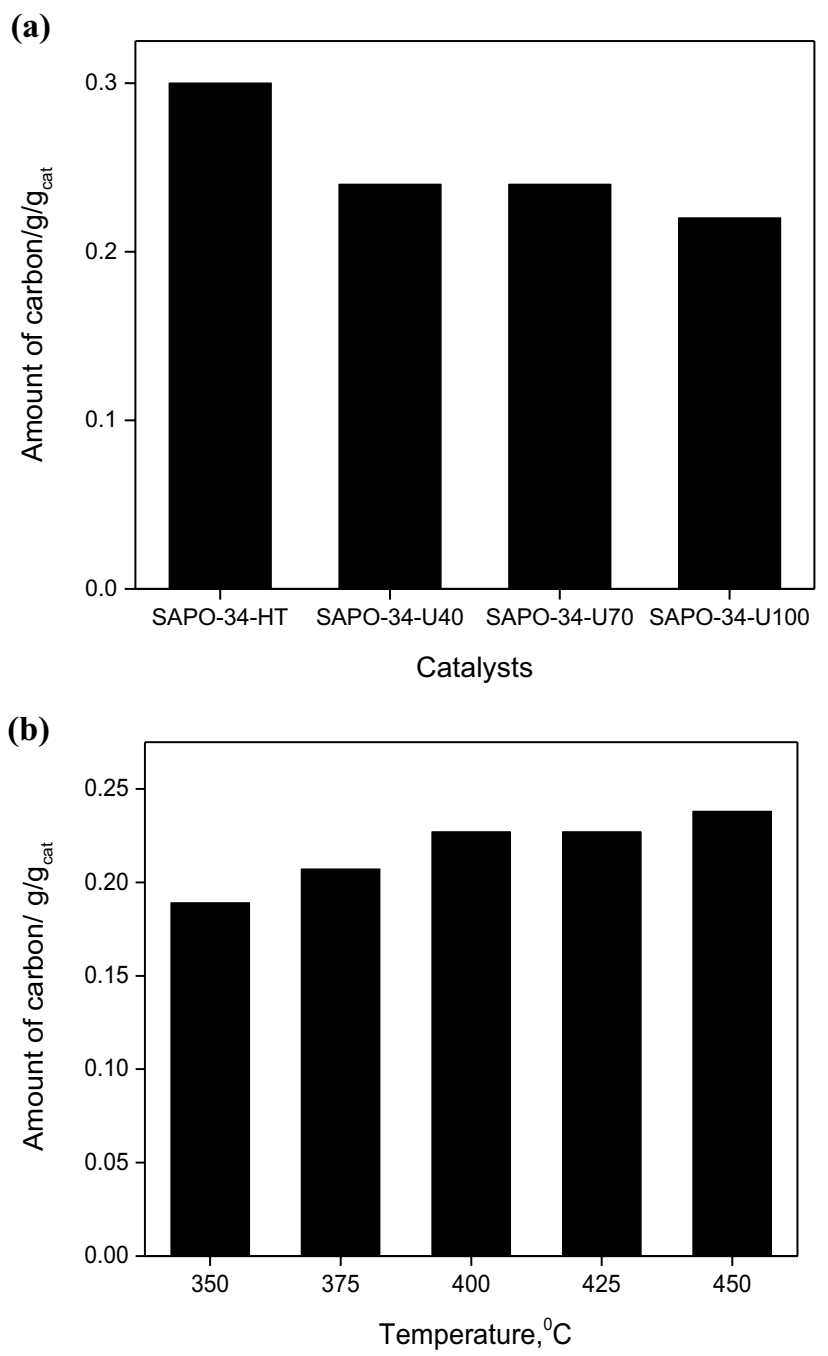

Fig. 7 The amount of carbon deposited per gram of the catalyst: a SAPO-34-HT, SAPO-34-U40, SAPO-34-U70, SAPO-34-U100 (at $450{ }^{\circ} \mathrm{C}$ ) and b SAPO-34-U40 (from 350 to $450{ }^{\circ} \mathrm{C}$ ). Reaction conditions: $\mathrm{CH}_{3} \mathrm{OH} / \mathrm{N}_{2}=60 / 40$, contact time $=2.05 \mathrm{~g}_{\text {cat }} \mathrm{min} \mathrm{ml}^{-1}$ with respect to methanol, catalyst $=0.2 \mathrm{~g}$

According to the results in Fig. 7b, it can be concluded that the amount of carbon deposition increases with increasing temperature. At $450{ }^{\circ} \mathrm{C}$, the amount of carbon deposition is higher (0.24). Generally, a high operating temperature enhances the reactions involved in coke formation such as oligomerization, cyclization, hydrogen transfer and alkylation to yield larger hydrocarbon species. At $350{ }^{\circ} \mathrm{C}$ catalyst deactivates rapidly and the amount of carbon deposition is lower (0.189) in this temperature. Ethylene and propylene, which are first hydrocarbons formed during MTO reaction, are not likely to produce aromatic hydrocarbons at low temperature. At temperature range of $375-425{ }^{\circ} \mathrm{C}$, the amount of formed coke is equally $(0.2)$, it means that the character of coke is similar at these temperatures [12]. The reason of 
low coke amount at these temperatures was explained in previous text.

\section{Conclusions}

Methanol-to-olefin reaction was investigated over SAPO34-HT (prepared hydrothermally), SAPO-34-U40, SAPO34-U70, SAPO-34-U100 (synthesized sonochemically) catalysts. Catalysts, synthesized sonochemically, were used to elucidate the effect of frequency of ultrasound waves on their catalytic performance, especially in terms of lifetime and selectivity toward light olefins and are compared with results obtaining over SAPO-34 catalyst, synthesized using conventional hydrothermal method. The product distribution in MTO process and coke deposition over catalysts synthesized hydrothermally and sonochemically were different, but over SAPO-34-U40, SAPO-34-U70 and SAPO-34-U100 were almost similar. According to physico-chemical analysis, SAPO-34-HT has lower surface area, lower crystallinity and it deactivates rapidly. Physico-chemical properties of catalysts prepared sonochemically are almost the same, except surface area, which is higher in SAPO-34-U40 in comparison to others. This catalyst was tested in MTO reaction at $350-450{ }^{\circ} \mathrm{C}$ temperature range. The higher yield $\sim 97 \mathrm{wt} \%$ (31.4 wt $\% \mathrm{C}_{2=}, 49.4 \mathrm{wt} \% \mathrm{C}_{3=}$ and $16.1 \mathrm{wt} \% \mathrm{sumC}_{4=}$ ) of light olefins was obtained at $375{ }^{\circ} \mathrm{C}$ and this temperature was found as an optimal temperature for MTO reaction over SAPO-34-U40 catalyst.

The lower amount of coke was determined at $350{ }^{\circ} \mathrm{C}$, the higher at $450{ }^{\circ} \mathrm{C}$. The character of coke deposited over SAPO-34-U40 was similar for $375-425{ }^{\circ} \mathrm{C}$ temperatures.

Acknowledgements We would like to thank Matthias Schneider for XRD and Benjamin Paul for SEM results.

Open Access This article is distributed under the terms of the Creative Commons Attribution 4.0 International License (http://creativeco mmons.org/licenses/by/4.0/), which permits unrestricted use, distribution, and reproduction in any medium, provided you give appropriate credit to the original author(s) and the source, provide a link to the Creative Commons license, and indicate if changes were made.

\section{References}

1. Kvisle S, Fuglerud T, Kolboe S, Olsbye U, Lillerud KP, Vora B (2008) Methanol-to-hydrocarbons. In: Handbook of heterogeneous catalysis, vol. 6, 2nd edn. Wiley-VCH, Weinheim, pp 2950-2964

2. Lefevere J, Mullens S, Meynen V, Noyen JV (2014) Structured catalysts for methanol-to-olefins conversion: a review. Chem Pap 68(9):1143-1153

3. Askari S, Halladj R, Sohrabi M (2012) An overview of the effects of crystallization time, template and silicon sources on hydrothermal synthesis of SAPO-34 molecular sieve with small crystals. Rev Adv Mater Sci 32:83-93
4. Fuentes GA, Bartholomew CH (1997) Catalyst deactivation. In: Proceedings of the 7th international symposium, Cancun, Mexico, pp 159-166

5. Qi Y, Wang G, Liu Z, Xu L, Gao X, Cui W (2001) 24-P-28-coke species and coking mechanism of SAPO-34 in MTO process. Stud Surf Sci Catal 135:278

6. Ahmadi SM, Askari S, Halladj R (2013) A review on kinetic modeling of deactivation of SAPO-34 catalyst during methano to olefins (MTO) process. AFINIDAD LXX 562:130-138

7. Razavian M, Halladj R, Askari S (2011) Recent advances in silicoaluminophosphate nanocatalysts synthesis techniques and their effects on particle size distribution. Rev Adv Mater Sci 29:83-99

8. Hajiashrafi T, Kharat AN (2013) Study of preparation methods and their effect on the morphology and texture of SAPO-34 for the methanol to olefin reaction. React Kinet Mech Catal 108:417-432

9. Peyman E, Shohreh F, Siamak AT (2011) Effect of synthesis parameters on phase purity, crystallinity and particle size of SAPO-34. Iran J Chem Chem Eng 30:29-36

10. Charghand M, Haghighi M, Saedy S, Aghamohammadi S (2014) Efficient hydrothermal synthesis of nanostructured SAPO-34 using ultrasound energy: physicochemical characterization and catalytic performance toward methanol conversion to light olefins. Adv Powder Technol 25:1728-1736

11. Charghand M, Haghighi M, Aghamohammadi S (2014) The beneficial use of ultrasound in synthesis of nanostructured Ce-doped SAPO-34 used in methanol conversion to light olefins. Ultrason Sonochem 21:1827-1838

12. Askari S, Halladj R, Sohrabi M (2012) Methanol conversion to light olefins over sonochemically prepared SAPO-34 nanocatalyst. Microporous Mesoporous Mater 163:334-342

13. Sharifi Pajaie H, Taghizadeh M (2015) Ultrasonic and microwave pretreatment for hydrothermal synthesis nanosized SAPOs and their catalytic performance in MTO reaction. Int J Eng 28:330-337

14. Gedanken A (2004) Using sonochemistry for the fabrication of nanomaterials. Ultrason Sonochem 11:47-55

15. Jenkins R, Snyder RL (1996) Introduction to X-ray powder diffractometry. John Wiley and Sons Inc., New York

16. Salmasi M, Fatemi S, Hashemi SJ (2012) MTO reaction over SAPO-34 catalysts synthesized by combination of TEAOH and morpholine templates and different silica sources. Sci Iran C 19(6):1632-1637

17. Mar HS (2009) Catalytic conversion of methanol/dimethylether to light olefins over microporous silicoaluminophosphates catalysts. A thesis submitted for the degree of master of engineering

18. Arbatani HN, Daryan JT, Kohdami FK (2014) The synthesis of SAPO-34 at different crystallization temperature and its catalytic performance for methanol to olefins reaction. Iran J Chem Eng 11:31-39

19. Dahl IM, Mostad H, Akropiaye D, Wendelbo R (1999) Structural and chemical influences on the MTO reaction: a comparison of chabazite and SAPO-34 as MTO catalysts. Microporous Mesoporous Mater 29:185-190

20. Izadbakhsh A, Farhadi F, Khorasheh F, Sahebdelfar S, Asadi M, Feng YZ (2009) Effect of SAPO-34's composition on its physicochemical properties and deactivation in MTO process. Appl Catal A 364:48-56

21. Wang P, Lv A, Hu J, Xu J, Lu G (2012) The synthesis of SAPO-34 with mixed template and its catalytic performance for methanol to olefins reaction. Microporous Mesoporous Mater 152:178-184

22. Lee YJ, Baek SC, Jun KW (2007) Methanol conversion on SAPO34 catalysts prepared by mixed template method. Appl Catal A 329:130-136

Publisher's Note Springer Nature remains neutral with regard to jurisdictional claims in published maps and institutional affiliations. 